\title{
Pathologists and head injuries
}

As an instrument of audit the necropsy is in decline, even in teaching hospitals, which ought to know better. ${ }^{12}$ As an instrument of scientific inquiry it is apt to seem old fashioned beside the electron microscope and the armamentarium of the chemical pathologist and the immunologist. Necropsies are, however, still widely performed on the victims of trauma, though their purpose is neither to audit clinical care nor to further our understanding of the complex pathological results of trauma. Indeed, the forensic pathologist's need to provide the coroner (or the procurator fiscal) with an immediate opinion about the cause of death, and the pressure on him or her to move on to the next slab or to the next court hearing, militate against detailed pathological research on accidental deaths.

The divergence of practical and research needs has been a particular hindrance in studies of brain damage after head injury, because of the need for the whole brain to be in fixative for three weeks before standard slices are examined both macroscopically and microscopically. Just how much can be learned by academic pathologists when their forensic colleagues provide them with unsliced brains for detailed dissection is shown from the series of papers from Adams and Graham and their various colleagues in Glasgow during the past decade. Their most recent report summarised their findings in a consecutive series of 151 head injuries that had been referred to a regional neurosurgical unit. ${ }^{3}$ Compared with the more commonly reported series from city mortuaries, ${ }^{4}$ which consist of victims who had died at the scene or very soon after injury, the Glasgow brains had a high incidence of damage attributable to pathophysiological events occurring subsequent to injury. Hypoxic and ischaemic damage was more often found than not, as were lesions due to raised intracranial pressure; these are often recognisable only after careful microscopy of the well-fixed brain. Systematic neuropathological examination of this kind makes it possible to distinguish between impact and secondary damage and to discover the importance of various avoidable factors in management which may have contributed to death. ${ }^{56}$ Such factors may be intracranial or extracranial, or both, and their frequency provides clinicians with a form of audit similar to that so successfully applied to elucidating the causes of maternal mortality.

The pathology studies from Glasgow are of particular value because the brains examined belonged to patients who had been systematically studied in life as part of the international data bank of severe head injuries. ${ }^{7}$ As a result detailed correlations could be made not only with clinical features but with investigations such as measurement of intracranial pressure ${ }^{8}$ and computed tomography. ${ }^{9}$ How far the findings in fatal cases indicate what lesions are likely to account for persisting clinical deficits in disabled survivors remains uncertain, but some of the widespread secondary lesions found in patients dying after several hours or days may well occur, to a less extent, in survivors. ${ }^{10}$ Some evidence of the extent and distribution of lesions in survivors has come from studies of CT scans done one to two years after injury. ${ }^{11}$

Another contribution of the Glasgow neuropathologists has been the development, in collaboration with statisticians, of a quantitative method for assessing the severity and location of cerebral contusions. ${ }^{12}$ Severe contusions were found only when there was a skull fracture, but a third of such patients had talked soon after their injury; their death was usually due to raised intracranial pressure resulting from swelling of the brain associated with the contusions. Analysis of the localisation of cerebral contusions in relation to fracture site, using this quantitative method, has thrown serious doubt on the concept of contrecoup-long cherished by pathologists and copied from one textbook to another. Contusions may occasionally be found opposite the site of a blow to the head, but when the distribution of contusions was analysed systematically they proved to be most common in the frontal and temporal lobes, regardless of the site of the fracture. Even when a vault fracture was confined to one side of the skull the contusions were usually bilateral, more or less symmetrically distributed.

At last pathologists are beginning to turn away from descriptive analogies drawn from the fruit garden and the kitchen in favour of measuring what they see, and are attempting to calculate differences rather than depending on adjectives of quality and adverbs of quantity.

1 Roberts WC. The autopsy: its decline and a suggestion for its revival N Englf Med 1978;299:332-8.

2 Cameron HM, McGoogan E, Watson H. Necropsy: a yardstick for clinical diagnosis. $\mathrm{Br}$ Med 7 1980;281:985-8.

${ }^{3}$ Adams JH, Graham DI, Scott G, Parker LS, Doyle D. Brain damage in fatal non-missile head injury. F Clin Pathol $1980 ; 33: 1132-45$.

4 Freytag E. Autopsy findings in head injuries from blunt forces. Arch Pathol 1963;75:402-13.

5 Rose J, Valtonen S, Jennett B. Avoidable factors contributing to death after head injury. Br Med $\mathcal{Y} 1977$;ii:615-8.

6 Jennett B, Carlin J. Preventable mortality and morbidity after head injury Injury 1978;10:31-9.

7 Jennett B, Teasdale G, Braakman R, Minderhoud J, Heiden J, Kurze T. Prognosis of patients with severe head injury. Neurosurgery 1979;4: 283-8.

8 Adams JH, Graham DI. The relationship between ventricular fluid pressure and the neuropathology of raised intracranial pressure. Neuropathol Appl Neurobiol 1976;2:323-32.

- Snoek J, Jennett B, Adams JH, Graham DI, Doyle D. Computerised tomography after recent severe head injury in patients without acute $N$ intracranial haematoma. F Neurol Neurosurg Psychiatry 1979;42:215-25.

10 Jennett B, Teasdale G. Management of head injuries. Contemporary neurology 20. Philadelphia: Davis Co, 1981.

11 Van Dongen KH, Braakman R. Late computer tomography-diagnosis of severe head injury. Neurosurgery 1980;6:14-22.

12 Adams JH, Scott G, Parker LS, Graham DI, Doyle D. The contusion $\omega$ index: a quantitative approach to cerebral contusions in head injury. Neuropathol Appl Neurobiol 1980;6:319-24. 